\title{
Macroeconomic Uncertainty, Consumer Sentiments, Consumption Expenditures And US Fixed Private Investment Growth
}

Rexford Abaidoo, University of Maryland Eastern Shore, USA

\begin{abstract}
Using Johansen Cointegration and Error Correction frameworks, as well as Granger Causality test Procedures, this study analyze both short and long-run relationships, and direction of causal association between US fixed private investment growth and selected explanatory variables. Test results based on quarterly time series data spanning the period (1960 -2010) shows deviations from equilibrium in fixed private investment growth tend to be corrected relatively faster than this study expected. This study also finds significant long-run and causal relationships between macroeconomic uncertainty, consumer sentiments, growth in consumption expenditures, and US fixed private investment growth.
\end{abstract}

Keywords: US Fixed Private Investment Growth; Consumer Sentiments; Growth in Consumption Expenditure; Error Correction Model; Granger Causality Test

\section{INTRODUCTION}

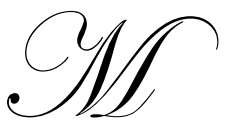

acroeconomic uncertainty (a remnant of 2008 economic shock) continues to have significant constraining effect on general growth trajectory of the US economy. Although weaker than expected GDP growth characterizing current (2010-2011) economic conditions pervades almost every economic sector, the constraining effect of the shock seems to be more pronounced in fixed private investment growth. Analysis of recent macroeconomic data on GDP growth and general investment pattern on the US economy show that various programs put in place to provide a boost to the economy has had minimal effect in bringing growth in fixed private investments to post recession (2008) levels. For instance, available quarterly data indicates fixed private investment growth recorded negative percentage growth in the second quarter of 2007 prior to the onset of the 2008 recession; this negative growth persisted until relatively weak positive growth at the beginning of the first quarter of 2010. This condition, among others continue to spur growing perception that prevailing macroeconomic uncertainty (a lingering impact of 2008 recession) has contributed significantly to weak recovery trend characterizing the US economy. The view that depressing effects of post-recession macroeconomic uncertainties continue to exert significant negative impact on fixed private investments and GDP growth as a whole is further supported by leading economic indicators. Trend in GDP growth since the economic collapse for instance; continue to be significantly weak, with the housing market and other key sectors of the economy still performing at levels far below pre-recession levels.

The literature on fixed private investment growth and macroeconomic uncertainty nexus is largely in support of an inverse relationship between the degree of prevailing macroeconomic uncertainty and rate of growth in fixed private investment. Firat Demir (2009), Federer (1993), Moguillansky (2002) have all found significant inverse association between prevailing macroeconomic uncertainty and growth in private investments in both developed and developing economies. For the purpose of this study, Fixed Private Investment defines investment expenditures by private enterprises, corporate firms and households on fixed assets; often geared towards provision of durable and non-durable goods and services for the general public. For most analysts, sustained growth in these investment expenditures over the years has served as an indicator of long-term investor confidence in the US economy, and prospect of sustained growth in GDP in the near future all things being equal. Reviewed economic 
data from Bureau of Economic Analysis however, show that uncertainties in the macroeconomic environment continue to impact negatively on most key economic indicators as well as fixed private investment growth in the US economy.

Macroeconomic theory posits that fixed private investments growth is predominantly influenced by variability in prevailing interest rate (Keynesian theory of investments). Significant portion of the growth in fixed private investment growth have consequently been found to exhibit negative association with prevailing interest rate: that is, as interest rate experience upward trend, the propensity to invest among firms (who borrow to invest in capital goods) tend to decline and vice versa all things being equal. Empirical evidence have further shown that there also exists autonomous level of private investment growth that is not subject to fluctuations in interest rates, or whose variability is not fully explained by the level of ongoing or prevailing interest rate vacillations. Consequently, in a typical investment growth framework, two parameters are often derived; one to measure sensitivity of investment to changes in interest rate and another parameter to capture component of investment growth which is independent of fluctuations in interest rates. Thus, a typical empirical investment model tends to capture both the autonomous and induced components of investment growth. Available fixed private investment data on US economy show that variability in current growth in fixed private investment cannot be fully explained by relative fluctuations or existing interest rates levels. The data rather suggests the trend might be explained more by other economic and external factors such as lingering macroeconomic uncertainty, general negative consumer sentiments and other core factors aside the traditional concept based on prevailing interest rates fluctuations.

Quarterly data sourced from FRED (Federal Reserve Economic Data) (FED Missouri) for instance, documents the negative impact of both past and recent economic perturbations such as the 2008 economic shock on US fixed private investment growth. Percentage change in fixed private investment growth data show that growth trend plummeted into negative territory just before the unset of the 2008 economic shock. The data indicates fixed private investment growth declined by -0.4 percent in the third quarter of 2007 just before the economy declined into the recent recession (2008). This decline in fixed private investment growth continued until the downward trend peaked with a percentage decline of -0.6 percent in the fourth quarter of 2009. Data trend analysis further show that, this steady decline in fixed private investment growth persisted until the first quarter of 2010; when the trend recorded a positive growth margin of $0.5 \%$ for the first time after the 2008 recession.

Although quarterly fixed private investment growth data between the periods (1947-2010) exhibits significant variability in percentage growth, the trend over the last decade has been fairly positive with the exception of specific quarters in 2001, 2002 and 2007 to 2009. It is significant however, to point out that, percentage decline in fixed private investment growth over these periods (2001, 2002 and 2007 to 2009) all happened to have coincided with periods of macroeconomic decline, recession or post recession periods in US economic history according to the National Bureau of Economic Research. This condition to some extent lend credence to the position that recessionary and post recessionary macroeconomic conditions tend to have significant constraining effects on fixed private investment growth in the US economy. Thus, the current data to some degree reflects projected inverse relationship between fixed private investments growth and periods of macroeconomic uncertainty.

Condition of negative association between macroeconomic uncertainty (recession induced or otherwise) and fixed private investment growth seemed not far fetch; in that, basic theory of the firm and consumer behavior projects that rational firms, households and private investors will tend to calibrate future investments projects to be in sync with both prevailing and projected macroeconomic conditions in order to minimize loses. This projection is further supported to some degree by underlying principles of rational expectation theory propounded by John F. Muth (1961). This theory holds that individual investors and firms tend to act or make decisions utilizing all relevant available information; both present and information on expected future conditions to forecast and make projections about future events. Any apparent errors in these forecasts are then assumed to be result of random events. In other words, firms and individual investors tend to take into considerations prevailing information on economic trends in their investment decision making process. Consequently, prolonged erratic macroeconomic conditions are projected to heighten the degree of uncertainty with the potential to ultimately depress investment growth all things being equal. 
This study hinges on the premise that among factors identified in existing literature as having constraining effect on fixed private investment growth, macroeconomic uncertainty, consumption expenditure patterns and consumer sentiments might explain more of the variability in fixed private investment growth than interest rate. Based this premise, this study tests both short-run and long-run relationship between these three core variables (macroeconomic uncertainty, consumption expenditure trends and consumer sentiment vis-à-vis other traditionally identified variables) and fixed private investment growth. This study also verifies existence of causal relationships between fixed private investment growth and these key variables. The focus on consumption expenditures, consumer sentiments etc is based on the assumption that trends in consumer behavior (expenditures and expectations) tend to reflects prevailing economic uncertainties; and might explain more of the swings in fixed private investment growth in the US economy.

A key contribution of this study to existing literature stems from its focus on growth in consumption expenditure fluctuations, consumer sentiments and macroeconomic uncertainty as prime or the critical factors explaining variability in fixed private investment growth in the US economy. As indicated earlier, this study is modeled on the assumption that private fixed investment growth fluctuations could be explained more by specific non-traditional factors in the US economy than conditions such as interest rates fluctuations, activities of the Federal Reserve etc. The focus on consumption expenditures and specific sources of consumer sentiments instead of interest rates has been further informed by relatively weak growth in fixed private investments after the 2008 economic shock even though interest rates have been relatively low over this period. Available data provided by FRED show that persistently low interest rates since the 2008 recession have failed to spur desired growth in fixed private investments as expected; a condition which lends credence to growing perception that, factors other than traditionally verified factors, might explain significant portion of the behavior of current fixed private investment growth in the US economy.

Recent economic data for instance, show that although average US interest rates after the 2008 economic decline has been at its lowest level over time, fixed private investments growth has not responded adequately as most traditional models tend to predict. This condition to some extent question the rate of adjustment associated with proposed inverse relationship between prevailing lending or interest rate and growth in investments. For example, quarterly bank prime loan rates have averaged 3.25\% since the first quarter of 2009; however, this relatively low interest rate has failed to attract and generate the expected growth in fixed private investment after the 2008 recession. This study projects that this condition might explain the difficult recovery trend characterizing the current state of the US economy after the 2008 economic downturn. The goal of this study is not to minimize in any measure, the importance of interest rates, other Federal Reserve policies, global economic trends, stock market performance etc in US fixed private investment growth. Rather, this study hopes to highlight growing importance of other non-traditional factors impacting US fixed private investment growth.

Additionally, this study also seeks to show that general fluctuations in US macroeconomic environment due to business cycles tend to boost the role of the consumer (consumption expenditures and consumer sentiments) in explaining variability in fixed private investment growth in the US economy. The rest of the study is sectioned as follows: Review of the strength of the relationship between fixed private investment growth and macroeconomic uncertainty (induced by factors such as prevailing economic condition, globalization, activities of the FED, stock market performance, GDP growth, etc) is captured in Section 2. The section also assesses the link between consumption expenditure, consumer sentiments and fixed private investment growth. Section 3 introduces econometric tools and procedures used in modeling and testing for short and long-run impact of key variables of the study on US fixed private investments growth. The section additionally tests for causal relationships between key variables and fixed private investment growth. Section 4 tests the main assumptions of the study and presents analysis of the results. The study concludes by analyzing possible policy implications and how the results could influence future macroeconomic policies.

\section{MACROECONOMIC UNCERTAINTY AND FIXED PRIVATE INVESTMENT GROWTH}

Constraining effect of macroeconomic uncertainty on private investment growth is well documented in the macroeconomic uncertainty and investments growth nexus literature. Sources of macroeconomic uncertainty often analyzed in the general literature range from inflationary condition expectations, exchange rate fluctuations 
expectations, activities of the Federal Reserve etc. This study however finds that irrespective of the source of modeled macroeconomic uncertainty, the literature to a greater extent supports the case that the condition ultimately impacts negatively on the rate of growth in private investments. This study identifies four conditions of macroeconomy related uncertainties and argues that each uncertainty category will tend to impact fixed private investments growth negatively. The conditions include uncertain moves by the Federal Reserve (most investors interpret actions as a measure of the state of the economy), uncertain global economic outlook, erratic swings in stock market performance (measure of the strength of economic recovery), and economic growth prospect uncertainties.

Activities of the Federal Reserve have been studied closely by investments analysts, potential investors and most firms planning for future investment projects for decades. Policy actions by the Federal Reserve are often interpreted to highlight expected or projected future economic trend by most investors. Consequently, any action or inaction by the FED in any point in time tends to send signals which are rightly or wrongly interpreted by the business community. Interpretation of these policy moves or inactions ultimately impacts propensity to invest throughout the economy; a condition which affects rate of growth in investments. Any perceived uncertainty about how the FED might react to prevailing economic condition might depress rate of investments growth since investors will hold off decisions on long term projects until they can make sense of the prospects of their investments. Investors in the financial sector and firms whose operations depend on the financial sector tend to be heavily impacted by uncertainties associated with activities of the Federal Reserve.

Another key condition of uncertainty which impacts growth in fixed private investment in the US economy emanates from growing interdependence among economies around the world- globalization. Rapid growth in technological advances and ongoing growth in multinational corporations continue to accelerate rate of interconnection among economies around the world; this trend has made economies more dependent on each other for growth than ever before. This growing integration of national economies means any significant perturbation in economic activities in other parts of the world or in particular economic partner, readily send shocks through the global economic network to other key economies around the world. Economic crisis in a single economy is no longer an isolated incident but a condition with potential to perturb economic activities in other economies around the world. For instance, supply shocks to the auto parts industry in Japan brought about by the March 11 earthquake and the tsunami which followed, significantly impacted production activities in the auto industries in the US economy. Again, financial crisis in Greece in recent months and uncertainties about the strength of EU's economic recovery continue to influence investments decisions in the US economy and around the world to some degree. These externally induced economic and financial uncertainties makes investors more hesitant to embark on long term projects and other investments opportunities. Thus, general global economic performance uncertainties or decline in economic activities in an allied economy or trading partner has the potential to exert significant constraining effect on investment growth in the United States all things being equal.

Studies further show that sustain and appreciable stock market performance to a greater extent serves as a good indicator in assessing the strength and growth trajectory of an economy; and viability of future investments. Significant number of these studies found positive correlation between stock market performance and economic growth. Levine and Zervos (1998) for instance, found positive and significant correlation between stock market development and long run economic growth. Additionally, Surya and Neupane (2006) also found positive long term causal relationship between stock market performance and economic growth. Although majority of existing studies tend to support positive association between stock market performance and economic growth, this study contend that stock market performance in itself does not solely and directly determine the extent of economic growth. A well performing stock market rather tend to create the avenue and projects an image or condition of a healthy economy with positive growth prospects; this condition in turn impact other core economic variables such as fixed private investments growth etc which directly impacts economic growth. Consequently, prolong and erratic fluctuations in the stock market will induce uncertain economic growth prospects with the potential to significantly depress investment growth all else held constant.

Economic growth volatility or uncertainties about future growth trajectory of the US economy also constitutes significant constraining factor on fixed private investment growth. Significant capital outlay required to embark on fixed investment projects require accurate projections about future growth prospects of the US economy 
and long term viability of the investment. This is essential in that, potential cash flows from such investment projects are often realized in the long term; consequently, if current and immediate future growth prospect of the US economy is fraught with uncertainty, the propensity to invest declines, resulting in constrained growth in investments. This condition is plausible in that, all else held constant, firms or corporations will be less likely to undertake long term fixed investment project with substantial initial financial commitment, when projected growth prospect will not support realization of expected cash flows critical to break even or make a profit. Discussions so far, show that uncertain economic conditions in general tend to depress both current and future fixed investment growth.

\subsection{Measuring Macroeconomic Uncertainty}

The process of measuring macroeconomic uncertainty continues to evolve with growing understanding of the mechanisms responsible of such conditions. Reviewed literature shows marked evolution from the use of proxies, moving standard deviation as in the case of Ghosal and Loungani (2000)), to the use of generalized autoregressive conditional hetroskedastic model (GARCH) in measuring uncertainty as presented in Driver, Temple and Urga (2005) and Byrne and Davis (2002) respectively. Other studies reviewed adopted allied variables as proxy for condition of macroeconomic uncertainty. Beaudry et al. 2001, for instance, modeled macroeconomic uncertainty using level of inflation as proxy. Econometric techniques, such as ARCH developed by Engle (1982 (a processor to the use of the GARCH model),) have also allowed authors to measure uncertainty by estimating the conditional variance of variables under consideration.

In this study however, macroeconomic uncertainty or variability in macroeconomic conditions is presumed to be captured by fluctuations in the rate of growth in loan demand or bank lending behavior. The choice of fluctuations in loan demand as proxy for macroeconomic uncertainty is based on the following reasons: (1) The desire to contract loans for most investment projects tends to diminish during periods of economic uncertainty and vice versa; and, (2) banks tend to adjust interest rates to reflect any perceived uncertain conditions in the market place leading to contraction in loan demand and vice versa. Thus, demand for loans and bank lending behavior tend to reflects prevailing variability in a macroeconomic environment. The literature provides some evidence on how loan demand or bank lending behavior captures macroeconomic uncertainty. Simon H. Kwan (2010) for instance, finds that in uncertain economic environment, both large and medium size banks significantly tightened loan supply rates, ultimately diminishing demand for loans. Rhodes and Guner (2003) further conclude that economic uncertainty has significant negative effect on the supply of and demand for bank loans. Furthermore, Talavera, Tsapin and Zholud (2007) also documents that although bank-specific characteristic impact lending rates, banks normally enhance lending rate in periods when macroeconomic uncertainty is minimal. In other words, fluctuations in loan demand (bank lending rate) tends to reflect degree of prevailing macroeconomic uncertainty all things being equal.

\section{CONSUMPTION EXPENDITURES AND FIXED PRIVATE INVESTMENT GROWTH}

Complex preference and demand features characterizing the average consumer continue to be subject of intense study in the economics and marketing literature; and in the business field as a whole. The impact of consumption expenditure fluctuations on investment growth is not as immediate as key variables such as interest rates. The extent to which fluctuations in consumption expenditure influence changes in fixed private investment growth depends on existence of specific fundamental conditions. The magnitude of consumption expenditure's impact on investment growth for instance, depends to some degree on the time frame under consideration; that is whether the focus is on short-run or long-run case scenario. From the general Keynesian macroeconomic framework, disposable income is deemed to be either consumed or saved; that is $\mathrm{Y}^{\mathrm{d}}=\mathrm{C}_{\tau}+\mathrm{S}_{\tau}$. Consequently, in the short-run, increase in consumption expenditures all things being equal, will diminish remaining component of disposable income for savings $\left(\mathrm{S}_{\tau}=\mathrm{Y}^{\mathrm{d}}-\mathrm{C}_{\tau}\right)$. Lower than expected savings in the banks weakens their ability to meet demand for loans which ultimately bids up interest rates (demand for loan exceeding available supply). As Interest rate increases, projects which were profitable under prior rates on loans now becomes unprofitable resulting in diminished investments growth (in accordance with the inverse association between interest rates and investment growth). 
However, although rising in interest rate in the short-run may induce unintended condition of boosting savings due to the prospect of relatively higher interest on deposits; this study finds no evidence that such condition is enough to counter significant decrease in investments due to relatively high interest rates on loans in the short-run. Thus in the short-run excessive growth in consumption expenditure might negatively impact investment growth all things being equal. In the long run however, it is presumed that continual growth in consumption will induce increase in demand for goods and services bidding up prices. This condition makes related investment projects relatively profitable again, bringing about growth in investments in responds to growth in demand. Thus, the impact of growth in consumption expenditures on investments growth in general depends to some degree on the time period under consideration vis-à-vis other integral macroeconomic conditions.

This study however deems long-run projection of this framework (positive relationship) as the plausible relationship between growth in consumption expenditures and rate of growth in investments. This positive relationship tends to garner more support among economists, and form the basis of significant number of corrective macroeconomic policies pursued in the US economy over the years. For instance, extensive Federal tax cut in the wake of the 2008 recession geared towards promoting consumption and investments growth in the US economy was influenced by perceived positive causal relationship between the two variables. Positive long-run association between growth in consumption expenditure and investments growth is also supported by existing literature. Jeffery Summers (1990), showed that contrary to general perception, cyclical fluctuations in personal consumption expenditure growth does not correlate negatively with cyclical fluctuations in investment growth; a case which supports condition of positive long-run relationship between growth in consumption expenditure and investments. The case for positive association between the two variables is further strengthened by the fact that significant component of investments made in the private sector are demand driven. Consequently, sustained growth in consumption expenditures all things being equal, highlight direction of growth in demand, which in turn elicits investments growth necessary to meet the growing demand. This study consequently projects significant positive relationship between growth in consumption expenditure and growth in fixed private investments in the US economy.

\section{CONSUMER SENTIMENTS AND INVESTMENTS GROWTH}

Consumer sentiments (confidence) in this study define the extent or degree of optimism or otherwise about the state of the US economy expressed by the average US consumer through demand and savings behavior. It captures general perceptions of the average consumer about the current state and immediate future trajectory of the US economy; and how the condition impacts his/her wellbeing. This study adopts consumer sentiments index as measured by the University of Michigan consumer sentiments index. The general view on the relationship between consumer sentiments and investments growth seems to support significant causal relationship between the two variables. John Heim (2010) for instance, finds that causation runs from consumer confidence to consumption and investments growth with no feedback effect. Additionally, the general literature addressing the dynamic association between consumer sentiments and growth in investment suggests consumer sentiments have significant impact on investment growth. Rajeev and Vasquez (2010) for example found that consumer sentiments and confidence are key causal factors in investments growth especially in the technology industry.

This study projects that negative or unfavorable consumer sentiments about the state of the US economy will results in slower than expected or decline in growth in investments and vice versa. This position stems from the assumption that the average rational investor tend to interpret prevailing market sentiments (positive or negative) as indication of lower than expected or a prospect of impending growth in demand and adjust short and long term investments accordingly. Consequently this study projects significant causal association between consumer sentiments and investment growth. A favorable consumer sentiment is expected to provide the needed impetus for growth in investments and ultimately economic growth; however, unfavorable or negative sentiments about the state of the economy will tend to stifle and depress investment growth.

\section{VARIABLES AND DATA}

Apart from consumer sentiment data from the University of Michigan Consumer Sentiment index database, data on other variables employed in the study have been sourced from St. Louis FED; Federal Reserve Economic 
Data database (FRED). Data series span the period 1960 to 2010; and the variables are captured in quarterly series. Key variables tested in this study include Fixed Private Investment growth (FPI), inflation (INF), effective federal fund rate (EFFR), personal consumption expenditure (services) (PCES), bank prime loan rates (BPLR), bank loan growth (BL) and consumer sentiment variable (CONS). The goal is to use specific features of individual variables to determine both long and short-run dynamic relationships as well as causal associations between FPI and consumption expenditure, consumer sentiments and a proxy for macroeconomic uncertainty.

\section{ECONOMETRIC MODELS AND TESTS}

Four key econometric tests are conducted using appropriate models. The tests involve verifying specific characteristics of key variables employed in the study, determining long-run and short-run interactions between FPI and selected explanatory variables, and verifying possible causal interactions between key explanatory variables and fixed private investment growth. The order of integration of variables is first determined using the Dicky-Fuller Generalized Least Square (DF-GLS) Unit Root test procedure. This test is followed by cointegration and error correction tests. Finally, causality test as defined by Granger (1969) is conducted. Table 1 presents results of unit root test for stationary conditions of individual variables employed in the study.

DF-GLS test for unit root (subject to specific lags) results captured in table 1 shows that selected variables, with the exception of (INFL) are all integrated in the order (1), i.e. I(1). Consequently, INFL variable is omitted from cointegration test for long-run relationships between selected variables and fixed private investment growth.

Table 1

DF-GLS Test for Unit Roots

\begin{tabular}{|c|c|c|c|}
\hline Variables & DFGLS stats & Lags & Results \\
\hline FPI & -1.825 & 0 & $\mathrm{I}(1)$ \\
\hline EFFR & -2.084 & 0 & $\mathrm{I}(1)$ \\
\hline BPLR & -2.015 & 0 & $\mathrm{I}(1)$ \\
\hline $\mathrm{BL}$ & -1.641 & 0 & $\mathrm{I}(1)$ \\
\hline PCES & -2.206 & 1 & $\mathrm{I}(1)$ \\
\hline INFL & -2.151 & 1 & $\mathrm{I}(0)$ \\
\hline CONS & -2.427 & 1 & $\mathrm{I}(1)$ \\
\hline
\end{tabular}

NB: Only (INFL) variable is integrated in the order I(0)

\subsection{Test for Long-run Relationships: Cointegration Analysis}

Table 2 presents results of cointegration test for long-run relationship between fixed private investment growth and key independent variables employed in the study with the required integrating order I(1).

Table 2

Johansen Test for Cointegration

\begin{tabular}{lcccc}
\hline Variables & $\begin{array}{c}\text { Null } \\
\text { Hypothesis }\end{array}$ & $\begin{array}{c}\text { Alternative } \\
\text { Hypothesis }\end{array}$ & $\begin{array}{c}\text { Trace } \\
\text { Statistics }\end{array}$ & $\begin{array}{c}\text { Critical } \\
\text { Value } \\
\mathbf{5 \%}\end{array}$ \\
\hline FPI(EFFR) & $\mathrm{r}=0$ & $\mathrm{r} \geq 1$ & 11.5 & 15.41 \\
FPI(BPLR) & $\mathrm{r}=0$ & $\mathrm{r} \geq 1$ & 8.79 & 15.41 \\
FPI(BL) & $\mathrm{r}=0$ & $\mathrm{r} \geq 1$ & 34.23 & 15.41 \\
FPI(PCES) & $\mathrm{r}=0$ & $\mathrm{r} \geq 1$ & 26.65 & 15.41 \\
FPI(CONS) & $\mathrm{r}=0$ & $\mathrm{r} \geq 1$ & 42.2 & 15.41 \\
\hline
\end{tabular}

Cointegration results presented in table 2 supports existence of long-run relationship between three out of five core variables of this study and fixed private investment variable (FPI). Johansen's approach to cointegration in this test supports condition of long-run relationship between rate of growth in bank loans supply and fixed private investments growth. Similar long-run relationship condition is also found between growth in personal consumption expenditures in the services sector of the US economy, consumer sentiments, and fixed private investments growth. 
The test however, failed to document any significant long-run relationship between effective federal fund rate fluctuations, bank prime lending rate and fixed private investment growth. This outcome show that, although, consumer sentiments, personal consumption expenditure growth and bank loan demand growth rates tend to exhibit extreme variability in individual trends, they ultimately exhibits long term association with growth in fixed private investments in the US economy.

\subsection{Short-Run Model of Fixed Private Investment Growth: Error Correction Approach}

In table 2, I presented results of long-run relationship dynamics between key variables employed in this study and Fixed Private Investments growth. However, to test for the pace of recovery in Fixed Private Investment growth from any perturbation or distortion to relative state of equilibrium (in light of other independent variables), short-run error correction model test is conducted. This procedure makes it possible to verify how fast deviations from equilibrium position in Fixed Private Investment growth are corrected. The Error Correction Model (ECM) in this case estimates or captures short-run rate of recovery associated with fixed private investment growth behavior vis-à-vis selected test variables on the US economy. The approach utilize lags of explanatory variables as well as an error correction term denoted in this study as: $\delta \boldsymbol{l t} v_{t-1}$. The error correction term $\delta \boldsymbol{l t}{ }_{t-1}$ consists of residual from longrun fixed private investment function from which results presented in table 2 were estimated. The general ECM estimation process is modeled as follows:

$$
\begin{aligned}
& \Delta f p i=\mathrm{b}_{0}+\beta_{i \mathrm{t}} \Delta e f f r_{i \mathrm{t}}+\beta_{i \mathrm{t}} \Delta e f f r_{\mathrm{it}-1}+\gamma \Delta f p i+\beta_{\mathrm{t}-1} \Delta b p l r_{\mathrm{it}}+ \\
& \beta_{\mathrm{it}} \Delta b p l r_{\mathrm{it}-1}+\beta_{\mathrm{it}}^{\Delta b l}+\beta_{\mathrm{it}} \Delta b l_{\mathrm{it}-1}+\beta_{\mathrm{it}} \Delta p c e \mathrm{~s}_{\mathrm{it}}+\beta_{\mathrm{it}} \Delta p c e s_{\mathrm{it}-1}^{+}
\end{aligned}
$$

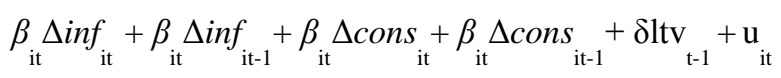

Where fpi, effr, bplr etc are variables already defined in data section. Equation 1 estimates error correction model using first difference and lagged independent variables as well as lagged differenced of the dependent variable denoted as $\gamma \Delta f p i{ }_{t-1}$. $\delta l t v{ }_{t-1}$ the error correction term in the equation captures residual estimates from long run cointegration test conducted earlier. The parameter $(\delta)$ in the error correction term estimates the disequilibrium error correction coefficient which captures the relative speed of adjustment after perturbation or shocks to growth in fixed private investment. Preliminary results based on equation (1) shows five of the variables in equation 1 are insignificant; these insignificant variables are subsequently eliminated from the error correction estimation. The rest of the variables are tested in an error correction framework and is modeled as follows:

$$
\begin{aligned}
& \Delta f p i i_{t}=b_{0}+\beta_{i t} \Delta e f f r_{i t-1}+\beta_{i t} \Delta b p l r_{i t}+\beta_{i t} \Delta b l+\beta_{i t} \Delta p c e s_{i t-1}+ \\
& \beta_{i t} \Delta \inf { }_{i t}+\beta_{i t} \Delta \inf { }_{i t-1}+\beta_{i t} \Delta \operatorname{cons}{ }_{i t}+\beta_{i t} \Delta \operatorname{cons}_{i t-1}+\delta l t v_{t-1}+u_{i t}
\end{aligned}
$$

Results of dynamic error correction model based on equation 2 are presented in table 3 .

Table 3

Error Correction Model for Fixed Private Investment Growth

\begin{tabular}{lccc}
\hline \multicolumn{1}{c}{ Variables } & Coefficient & Standard Error & T-Statistics \\
\hline$\Delta$ FPI & & & 3.01 \\
$\Delta$ LEFFR $_{\mathrm{t}-1}$ & 0.34712 & 0.115278 & -362 \\
$\Delta$ BPLR $_{\mathrm{t}}$ & -0.50561 & 0.139518 & 3.43 \\
$\Delta \mathrm{BL}_{\mathrm{t}}$ & 0.16828 & 0.049106 & 1.47 \\
$\Delta$ PPCES $_{\mathrm{t}-1}$ & 0.30652 & 0.208643 & 1.55 \\
$\Delta$ LINF $_{\mathrm{t}-1}$ & 0.27265 & 0.176324 & 1.98 \\
$\Delta \mathrm{INF}_{\mathrm{t}}$ & 0.3539 & 0.178928 & 6.07 \\
$\Delta$ CONS $_{\mathrm{t}}$ & 0.13126 & 0.21629 & 3.71 \\
$\Delta$ LCONS $_{\mathrm{t}-1}$ & 0.07899 & 0.021305 & -11.24 \\
cc $_{\mathrm{t}-1}$ & -0.73661 & 0.065544 & $\mathrm{~F}(9,191)=27.62$ \\
\hline $\mathrm{R}^{2}=0.57$ & & & 0 \\
\hline
\end{tabular}


Error correction coefficient estimate of approximately $\left(\mathrm{Ec}_{\mathrm{t}-1}\right)-0.74$ is significant with the correct sign. This coefficient estimate captures the speed of adjustments towards equilibrium after a shock to fixed private investment growth. It suggests that all things being equal, distortions to the equilibrium position of fixed private investment growth are corrected somehow faster than this study anticipated. The magnitude of the error correction coefficient (0.74) also depicts the adjustment rate at which distortions in fixed private investment growth in relation to performance of other independent variables tested are restored after a shock to the economy such as the 2008 economic shock. As noted, the error correction coefficient (approximately -0.74) projects relatively faster pace of recovery than this study anticipated; in that, this rate of adjustment does not reflect current trends in US fixed private investment growth. Reviewed data on fixed private investment growth show sustained weakening and negative percentage change in growth for most part since the 2008 economic shock. Consequently, this study expected relatively slower pace of adjustment; a condition which would have explained the current pace of recovery in fixed private investment growth. Both consumer sentiments and consumption expenditure variables have the expected positive sign suggesting positive association between individual variables and fixed private investment growth. However, uncertainty proxy (BL) failed to capture negative association with fixed private investment growth as expected; this failure to verify a negative association between macroeconomic uncertainty and fixed private investment growth could stem from specific features of the proxy used to capture condition of macroeconomic uncertainty.

\section{TEST FOR CAUSAL RELATIONSHIPS: GRANGER CAUSALITY APPROACH}

Causality test via Granger Causality Approach (Propounded by Granger (1969)) revolves around a basic principle which suggests that, if observed perturbation in variable (y) is found to normally occur after changes in another variable (u), then it is unlikely that changes in variable (u) will be caused by disturbances in variable (y). The reverse condition that changes in (u) rather causes changes in (y) is thus accepted as the likely condition explaining changes in variable (y) all things being equal. The Granger causality test procedure is based on the following premise: A variable (y) is presume to Granger-Cause changes in (u) if (u) can be better predicted using lagged values or histories of both (y) and (u) than it can using lagged values of (u) alone. This causality test approach is adopted in verifying causal relationships between fixed private investment growth and three key independent variables in the study. Prior test of individual variables indicated presence of unit root; critical steps are consequently taking to ensure that variables are integrated in proper order before the test for causality. $Y, \varnothing$ and $\mu$ in this test represents growth in consumption expenditures $(Y)$, a proxy for macroeconomic uncertainty $(\varnothing)$ and Consumer sentiments $(\mu)$ variables respectively; and $X$, represents quarterly growth in fixed private investment variable. (NB. All variables are captured in quarterly series). Causal relationship between these three core independent variables identified, and growth in fixed private investment is modeled together in an unrestricted equation as follows:

$$
\begin{aligned}
\mathrm{X}_{1}=\beta_{i t}{ }^{0} & +\beta_{1} X_{i t} X_{t-1}+\beta_{2{ }_{i t}{ } X_{t-2}}+\ldots \beta_{3} X_{t-p}+\delta Y_{t-1}+\delta Y_{t-2}+ \\
& . \delta Y_{t-p}+\psi \emptyset_{t-1}+\psi \emptyset_{t-2}+\ldots \psi \emptyset_{t-p}+\lambda \mu_{t-1}+\lambda \mu_{t-2}+\ldots \lambda \mu_{t-p}+\varepsilon
\end{aligned}
$$

Where $X_{t-1}$ and $X_{t-2}$ are lagged values of fixed private investment growth and $\left(Y_{t-1}\right.$ and $\left.Y_{t-2}\right),\left(\varnothing_{t-1}\right.$ and $\left.\emptyset_{t-2}\right),\left(\mu_{t-1}\right.$ and $\mu_{t-2}$ ) are lagged values of consumption expenditure, macroeconomic uncertainty and consumer sentiments respectively. $\varepsilon$, is the error term. Equation 3 tests the null hypotheses that individual variables, $Y, \emptyset$ and $\mu$ do not Granger cause fluctuations or changes in $\mathrm{X}$ or the three core independent variables do not Granger cause or influence changes in fixed private investment growth; the conditions are tested as follows:

$$
\begin{aligned}
& \mathrm{H}_{\mathrm{o}}: \delta_{1}+\delta_{2}+\ldots . \delta_{\mathrm{t}}=0 \\
& \mathrm{H}_{\mathrm{o}}: \psi_{1}+\psi_{2}+\ldots . \psi_{\mathrm{t}}=0 \\
& \mathrm{H}_{\mathrm{o}}: \lambda_{1}+\lambda_{2}+\ldots . \delta_{\mathrm{t}}=0
\end{aligned}
$$


A rejection or failure to reject these null hypotheses provides the basis for understanding causal associations or otherwise between key independent variables and fixed private investment growth.

Equations 4(a), 4(b) and 4(c) (all variables previously defined) on the other hand, models unrestricted regressions testing for the reverse or inverse causal relationships between fixed private investment growth and the three main independent variables of the study. Equation $4 \mathrm{a}$ for instance, test the condition that fixed private investment growth does not Granger cause changes or fluctuations in consumption expenditures; equation $4 \mathrm{~b}$ verifies whether fluctuations in fixed private investment growth rather promotes or causes swings in macroeconomic uncertainty, and $4 \mathrm{c}$ ascertain the possibility of Granger causality running from fluctuations in fixed private investment to changes in consumer sentiments.

$$
\begin{aligned}
& \mathrm{Y}_{1}=\delta_{0}+\delta_{1} Y_{t-1}+\delta_{2} Y_{t-2}+\ldots \ldots \delta_{3} Y_{t-p}+\beta_{1} X_{t-1}+\beta_{2} X_{i t}+\ldots \ldots \beta_{3} X_{t-p}+\varepsilon \\
& \emptyset_{1}=\psi_{0}+\psi_{1} \emptyset_{t-1}+\psi_{2} \emptyset_{t-2}+\ldots \ldots \psi_{3} \emptyset_{t-p}+\beta_{i t} X_{t-1}+\beta_{i t} X_{t-2}+\ldots \beta_{3} X_{t-p}+\varepsilon \\
& \mu_{1}=\lambda_{0}+\lambda_{1} \mu_{t-1}+\lambda_{2} \mu_{t-2}+\ldots \ldots \lambda_{3} \mu_{t-p}+\beta_{i t} X_{t-1}+\beta_{i t} X_{t-2}+\ldots \ldots \beta_{3 i} X_{t-p}+\varepsilon
\end{aligned}
$$

Based on equations $4 \mathrm{a} 4 \mathrm{~b}$ and $4 \mathrm{c}$, the null hypothesis that fixed private investment growth (X) does not Granger cause changes in $\mathrm{Y}, \varnothing$ or $\mu$ i.e. consumption expenditure, macroeconomic uncertainty and consumer sentiments respectively is also tested as follows:

$\mathrm{H}_{\mathrm{o}}: \beta_{1}+\beta_{{ }_{i t}}+\ldots . . \beta_{3 t}=0$

Using Granger's specification of causality, this study adopts Sims (1972) manipulation of F-statistics in testing for causality using equations (3) and $(4 \mathrm{a}, 4 \mathrm{~b} 4 \mathrm{c})$ to test the main hypotheses in equations $3 \mathrm{a}, 3 \mathrm{~b}, 3 \mathrm{c}$ and 5. Table 3 presents Granger causality test results between FPI and Consumer Sentiments (Cons), Macroeconomic Uncertainty (UN(BL)) and Growth in Consumption Expenditures (PCES).

Table 4

Granger Causality Test

\begin{tabular}{lllll}
\hline \multicolumn{1}{c}{ Null Hypothesis } & F- Statistic & P-Value & Lags & Decision \\
\hline (PCES) does not cause changes in (FPI) & 3.56 & 0.008 & 4 & Reject \\
(FPI) does not cause changes in (PCES) & 0.65 & 0.627 & 4 & Fail to Reject \\
(Cons) does not cause changes in (FPI) & 7.22 & 0.000 & 4 & Reject \\
(FPI) does not cause changes in (Cons) & 2.65 & 0.35 & 4 & Fail to Reject \\
(UN (BL does not cause changes in FPI) & 3.57 & 0.008 & 4 & Reject \\
(FPI) does not cause changes in UN(BL & 8.41 & 0.000 & 4 & Reject \\
\hline
\end{tabular}

Table 4 shows two of the null hypotheses tested could not be rejected. Four of the null hypotheses are however rejected. This outcome indicates consumption expenditure growth (PCES) all else held constant, Granger cause changes in fixed private investment growth in the US economy with no feedback effect. The third null hypothesis test result further documents that swings in consumer sentiments (Cons) significantly impact or Granger causes fluctuations in fixed private investment growth among various sectors of the US economy without significant feedback effect. Macroeconomic uncertainty however, is found to exhibit bi-directional causal relationship with fixed private investment growth. That is, the degree of prevailing macroeconomic uncertainty Granger causes fluctuations in fixed private investment growth with feedback effect. 


\section{CONCLUSION}

This study tested for long-run and short-run relationships as well as Granger causality associations between fixed private investments growth in the US economy and key variables such as growth in consumption expenditure, consumer sentiments, and macroeconomic uncertainty. Results show that there exist significant long-run relationships between growth in fixed private investments and key variables such as consumer sentiments, growth in consumption expenditure, and macroeconomic uncertainty. This study further finds that contrary to expectation, the speed of adjustment in fixed private investment growth after a shock to the system tends to be relatively faster; a condition which fails to explain the ongoing weak growth in fixed private investment after the 2008 economic shock. Finally, Granger causality test also finds significant unidirectional and bi-directional causal relationships between fixed private investment growth and consumer sentiments, consumption expenditure growth and macroeconomic uncertainty proxy. These findings could augment existing framework geared towards enhancing macroeconomic policy effectiveness, by offering alternative means of promoting growth in US fixed private investments.

\section{AUTHOR INFORMATION}

Rexford Abaidoo $\mathrm{PhD}$; is an Assistant Professor of Business Administration and Quantitative methods at the University of Maryland Eastern Shore. Teaching areas include corporate finance, business statistics, scientific methods in business and computer application in business. Research mainly focuses on dynamics of economic growth and recovery, international finance and competitiveness and consumer behavior. E-mail: rabaidoo@umes.edu

\section{REFERENCES}

1. Beaudry, Paul, Mustafa Caglayan, and Fabio Schiantarelli (2001), "Monetary instability, the predictability of prices, and the allocation of investment: An empirical investigation using U.K. panel data", American Economic Review 91: 648-62.

2. Byrne, J. P. and Davis, E. P. (2002), Investment and uncertainty in the G7, Discussion papers, National Institute of Economic Research, London.

3. Dhawan Rajeev and Harold Vasquez (2010) "U.S. Employment Growth and Tech Investment: A New Link", Georgia State University Working Paper.

4. Driver, C., Temple, P. and Urga, G. (2005), 'Profitability, capacity, and uncertainty: a model of UK manufacturing investment', Oxford Economic Papers 57(1), 120-141.

5. Federer, J. (1993) The Impact of Uncertainty on Aggregate Investment Spending, Journal of Money, Credit and Banking, 25, 30--48.

6. Ghosal, V. and Loungani, P. (2000), 'The differential impact of uncertainty on investment in small and large business', The Review of Economics and Statistics 82, 338-349.

7. Granger, C.W.J. (1969), "Investigating Causal Relations by Econometric Models and Cross-Spectral Methods", Econometrica, 37, 424-436.

8. Heim John (2010), The impact of consumer confidence on consumption and Investment Spending. Journal of applied business and economics Vol 11(2)

9. Lesotho Patrick (2006) An investigation of the determinants of private investment: The Case of Botswana. A mini-thesis submitted in partial fulfillment of the requirements for the degree of Masters (Structured) in Economics, University of the Western Cape.

10. Levine, R., and S. Zervos. 1998. "Stock Markets, Banks, and Economic Growth" American Economic Review, Vol. 88:537-58.

11. Loría, Eduardo, Y Brito, L.(2004) Is the Consumer Confidence Index a Sound Predictor of the Private Demand in the United States? Estudios de Economía Aplicada vol. 22 - 3 , 2004

12. Moguillansky, G. (2002) Investment and Financial Volatility in Latin America, CEPAL Review, 77, 45--63.

13. Muth, John F. 1961. "Rational Expectations and the Theory of Price Movements." Econometrica 29 (3): 315-35.

14. Rhodes and Guner (2003), Economic Uncertainty and Economic Crunch: Evidence From Emerging Market. Emerging Market Finance and Trade, Vol 39, no 4 pp 5-23 
15. Robert Engle. Autoregressive Conditional Heteroskedasticity with Estimates of the Variance of United Kingdom In $^{\circ}$ ation. Econometrica, (50):987\{1007, 1982.

16. Simon H. Kwan (2010) Financial Crisis and Bank Lending; Federal Reserve Bank of San Francesco Working Paper; 2010 11. http://www.frbsf.org/publications/economics/papers/2010/wp10-11bk.pdf

17. Sims, C. (1972), "Money, Income and Causality," American Economic Review, 62, 540-552

18. Summers Jeffery (1990) The macroeconomic correlates of Investments growth in the Soviet Union. Soviet Studies, 1990, Vol. 42 Issue 4, p795, 15p, 5 Charts

19. Surya, Bahadur G. C. and Neupane, S., 2006. "Stock Market and Economic Development: A Causality Test" The Journal of Nepalese Business Studies. 111(1): Dec.

20. Wooldridge, J M (2003) Introduction Econometrics: A modern Approach (2ed) Thomson, South-Western 